\title{
Imaging Journal of Clinical and Medical Sciences
}

\author{
Clinical Image
}

ISSN: 2455-8702

\section{Scrotal Mass}

\author{
El Rassi Patrick and Farhat Said ${ }^{\star}$ \\ ${ }^{1}$ University of Balamand, Saint Georges University Medical Center, Beirut, Lebanon \\ ${ }^{2}$ Lebanese University, Beirut, Lebanon
}

${ }^{*}$ Corresponding author: Farhat Said, University of Balamand, Saint Georges University Medical Center, Beirut, Lebanon, Tel: 009613636211; Fax: 009611443516; Email: saidfarhat@hotmail.com

Received: August 15, 2014; Accepted: September 08, 2014; Published: September 10, 2014

A 45-year-old man presented to the emergency room with abdominal pain and distention, dyspnea and a scrotal mass with absence of a visible penis as shown in the figure 1 below.

Abdominal circumference was $120 \mathrm{~cm}$, scrotum circumference was $80 \mathrm{~cm}$ and the height of the scrotum was $35 \mathrm{~cm}$. There were no signs of acute abdomen and preliminary routine laboratory labs were within normal except for minimally elevated transaminase levels.

Physical examination showed that the patient has ascites along with a compressible painful scrotum and he is known to have Hepatitis C. There were no signs of acute gastrointestinal bleeding or encephalopathy.
CT scan of the abdomen showed significant amount of free peritoneal fluid and a patent renal and splenic vein. EGD showed grade 3 esophageal varices.

Aspiration of the fluid was done and cytology showed SAAG $>1.1$ and did not reveal the presence of malignant cells. TSH and $\alpha-F P$ were negative.

The diagnosis was an abdominal ascites with an inguinal hernia. The presences of the hernia lead to the progressive enlargement of the scrotal sac, which was filled with fluid and intestines in this case. A splenorenal shunt and a repair of the hernia were done and the patient was discharged on the $4^{\text {th }}$ post operative day.

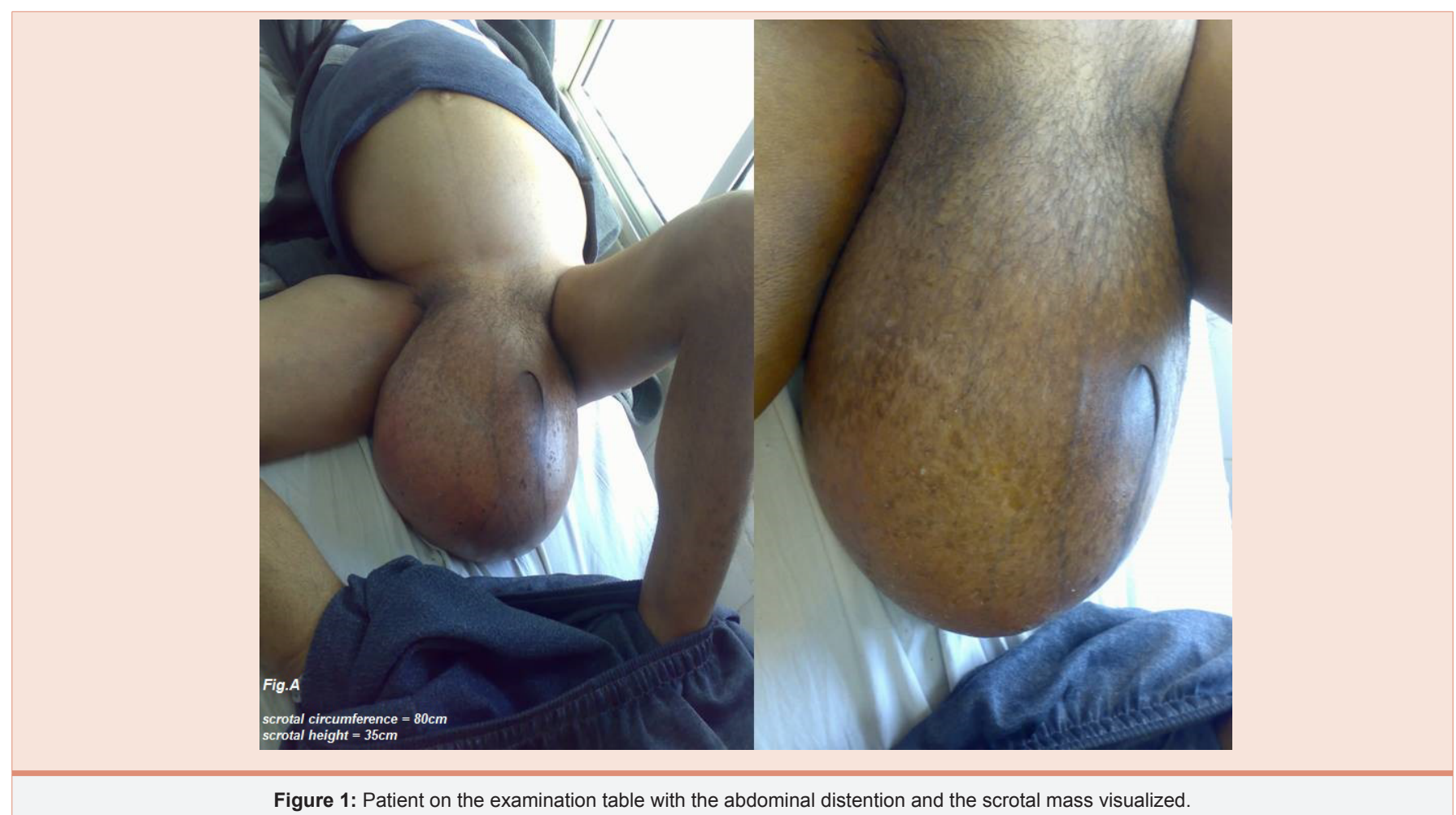

Copyright: () 2014 Patrick ER, et al. This is an open-access article distributed under the terms of the Creative Commons Attribution License, which permits unrestricted use, distribution, and reproduction in any medium, provided the original author and source are credited. 